\title{
PENGARUH TERAPI BEKAM TERHADAP PENURUNAN KADAR KOLESTEROL PADA PASIEN HYPERCHOLESTEROLEMIA DI RUMAH SEHAT AL-HIJAMAAH TAHUN 2014/2015
}

\author{
Sitti Aulia Hidayat ${ }^{1}$, Salsa Anggeraini ${ }^{2}$, Taufik Qul Hidayat ${ }^{3}$, and Rusli Malli ${ }^{4}$ \\ 1,2,3,4 Universitas Muhammadiyah Makassar \\ e-mail:aulia.hidavat@,rocketmail.com
}

\begin{abstract}
To know the effect of cupping therapy to decrease cholesterol levels in patients at Home Healthy hiperkolestrolemia Al-hijamaah in the year 2014/2015. Research observational analytic-numerical categorical pairs. Samples were hypercholesterolemic patients at Home Healthy Al-hijamaah in 2014/2015. Taken by using non-probability sampling technique with purposive sampling method. The primary data obtained directly from respondents, and analyzed by paired T test. The number of samples involved in this study were 45 respondents. Most of the samples were aged 20-45 years were 28 respondents (62.2\%), female 27 respondents (60\%), and average cholesterol levels before cupping therapy of $262.84 \mathrm{mg} / \mathrm{dl}$ and the average after cupping therapy $239.53 \mathrm{mg} / \mathrm{dl}$. In this study, the results of Test Independent t test $t$ test $=2.64$ with $p=0,010(p<0.05)$ which means that there are significant differences in cholesterol levels before and after cupping therapy.
\end{abstract}

Keyword : Hypercholesterolemia, cholesterol, dyslipidemia, cupping therapy, wet cupping therapy

\begin{abstract}
Abstrak
Untuk mengetahui efek terapi bekam terhadap penurunan kadar kolesterol pada pasien di Rumah Sehat hiperkolestrolemia Al-hijamaah pada tahun 2014/2015. Penelitian pasangan analitik-numerik observasional. Sampel adalah pasien hiperkolesterolemia di Home Healthy Al-hijamaah pada 2014/2015. Diambil dengan menggunakan teknik non-probability sampling dengan metode purposive sampling. Data primer diperoleh langsung dari responden, dan dianalisis dengan uji $T$ berpasangan. Jumlah sampel yang terlibat dalam penelitian ini adalah 45 responden. Sebagian besar sampel berusia 20-45 tahun adalah 28 responden (62,2\%), perempuan 27 responden (60\%), dan kadar kolesterol rata-rata sebelum terapi bekam 262,84 mg / dl dan ratarata setelah terapi bekam 239,53 $\mathrm{mg} / \mathrm{dl}$. Dalam penelitian ini, hasil Uji Independen uji $t$ uji $t=2,64$ dengan $p$ $=0,010(p<0,05)$ yang berarti ada perbedaan kadar kolesterol yang signifikan sebelum dan sesudah terapi bekam.
\end{abstract}

Kata kunci: Hiperkolesterolemia, kolesterol, dislipidemia, terapi bekam, terapi bekam basah

\section{PENDAHULUAN}

Masalah kesehatan yang sering dikhawatirkan masyarakat modern saat ini adalah kadar kolesterol yang terlalu tinggi atau dikenal dengan hiperkolesterolemia. ${ }^{1}$ Kolesterol merupakan salah satu lipid plasma yang berasal dari makanan (eksogen) dan dari sintesis lemak (endogen). ${ }^{2}$ Dalam kondisi normal kadar kolesterol total yang dibutuhkan tubuh yaitu sebanyak $<200 \mathrm{mg} / \mathrm{dl}$. Dan apabila melebihi dari $200 \mathrm{mg} / \mathrm{dl}$ akan menyebabkan penimbunan kolesterol di dalam dinding pembuluh darah, yang secara perlahan mengeraskan dinding pembuluh darah sehingga menghambat aliran darah dan menyebabkan aterosklerosis serta penyakit kardiovaskuler lainnya. ${ }^{3}$

Menurut World Health Organization (WHO) 15 juta jiwa kematian tiap tahunnya atau sekitar $30 \%$ oleh dari kematian total pertahunnya disebabkan oleh penyakit pembuluh darah salah satunya hiperkolesterolemia. Sekitar 4,5 juta jiwa diantaranya disebabkan oleh stroke yang disebakan karena peningkatan 
kadar kolesterol. ${ }^{4}$ Angka kejadian hiperkolesterolemia menurut penelitian MONICA (Monitoring trends and determinants of Cardiovascular Disease) di Jakarta menunjukkan bahwa kadar ratarata kolesterol total pada wanita 206,6 $\mathrm{mg} / \mathrm{dl}$ dan pria $199,8 \mathrm{mg} / \mathrm{dl}$. Terlihat pula kecenderungan meningkatnya angka ratarata dan prevalensi hiperkolesterolemia $(>6,5 \mathrm{mmol} / \mathrm{l})$ dengan bertambahnya umur. $^{5} \quad$ Sedangkan prevalensi hiperkolesterolemia menurut penelitian MONICA II di Indonesia, ditahun 2004, didapati $16.2 \%$ wanita dan $14 \%$ laki-laki. Pemberian obat golongan statin banyak digunakan oleh tenaga kesehatan sebagai obat penurunan kadar kolesterol. Statin berkerja menghambat pembentukan kolesterol dalam sirkulasi darah. ${ }^{6}$ Akan tetapi obat golongan statin mempunyai beberapa efek samping. Efek samping yang ditimbulkan oleh obat-obat golongan statin diantaranya mual, konstipasi, kram abdomen, sakit kepala, nyeri otot, dan gangguan hati pernah dilaporkan pada beberapa kasus. ${ }^{2}$ Berbagai efek samping dari statin dan tidak sedikitnya biaya yang dikeluarkan mengakibatkan berat untuk memilih obat tersebut sebagai obat pilihan dalam menurunkan kadar kolesterol darah.

Penelitian yang dilakukan subhi dengan judul perbedaan kadar gula darah pasien diabetes melitus pada pengobatan bekam di dapatkan hasil adanya perbedaan kadar gula darah sewaktu sebelum dan sesudah dilakukan bekam, hal ini menunjukan bahwa bekam sangat berpengaruh terhadap penurunan kadar gula darah penderita diabetes mellitus. ${ }^{10}$ Penelitian lain juga dilakukan oleh Jansen dengan judul efektifitas terapi bekam terhadap penurunan tekanan darah pada penderita hipertensi primer di dapatkan hasil bahwa adanya penurunan tekanan darah setelah dilakukan terapi bekam. ${ }^{11}$

Beberapa penelitian ilmiah ini menunjukkan bahwa berbekam memiliki manfaat penyembuhan yang begitu penting. Islam membolehkan berbekam, bahkan memerintahkannya. ${ }^{12}$ Terapi bekam merupakan cara penyembuhan penyakit yang telah dilakukan berabadabad lalu, terapi bekam bermanfaat membersihkan darah dari racun-racun sisa makanan, melancarkan peredaran darah, mengatasi gangguan tekanan darah yang tidak normal, mengatasi pengapuran pembuluh darah, memperbaiki permebilitas pembuluh darah, menghilangkan kejang-kejang dan sebagainya. ${ }^{13}$

Berdasarkan uraian dia atas, maka penulis ingin mengetahui apakah terapi bekam dapat menjadi solusi alternatif pada pasien dengan kadar kolesterol yang tinggi dan untuk itu penulis tertarik untuk melakukan penelitian yang berjudul Pengaruh Terapi Bekam Terhadap Penurunan Kadar Kolesterol Pada Penderita Hiperkolesterolemia di Rumah Sehat Al-Hijamaah.

\section{METODE}

Jenis penelitian ini adalah penelitian Pre Eksperiment dengan menggunakan rancangan One Group Pra-Post test Design yaitu penelitian ini dilakukan dengan cara memberikan pretest/ pengamatan awal terlebih dahulu sebelum diberikan intervensi. Setelah diberikan intervensi kemudian dilakukan kembali post-test pengamatan akhir Pada penelitian ini sebelum di lakukan intervensi dalam hal ini adalah terapi bekam, kadar kolesterol penderita akan di ukur (pre-test) kemudian setelah di lakukan terapi bekam kadar kolester penderita akan diukur kembali (post-test).

Populasi dalam penelitian ini adalah pasien yang akan melakukan bekam di Rumah Al- Hijamaah di jln. Cumi-cumi no 2 Makassar, yang akan di laksanakan dari tanggal 21 Desember 2014 sampai 21 Januari 2015.

Teknik pengambilan sampel pada penelitian ini dilakukan Menggunakan purposive sampling, dengan kriteria inklusi sebagai berikut : Laki-laki, usia >20thn, hiperkolestrolemia, tidak 
mengkomsumsi obat penurun kolesterol, tidak ada riwayat mendapatkan tindakan terapi bekam sekurang kurangnya 1 bulan dari waktu pelaksanaan penelitian, tidak menderita penyakit berat dan kronis dan bersedia. sampel minimal 35 orang.

Penelitian ini menggunakan satu sumber data yaitu menggunakan data primer yakni data dari hasil pemeriksaan kolesterol yang diambil secara langsung dari responden dengan menggunakan pre dan post test bekam. Data primer yang dikumpulkan dalam penelitian ini akan diolah menggunakan fasilitas komputer Statistical Program for Social Science (SPSS)

Analisa univariat pada penelitian ini bertujuan untuk melihat gambaran setiap variabel yang diteliti. Bentuk penyajiandata menggunakan tabel distribu si frekuensi dan selanjutnya dilakukan analisis terhadap tampilan data tersebut untuk mengetahui sebaran dari masingmasing variabel, setelah dilakukan skorkemudian dilihat berapa persentasenya.

Analisis bivariat dalam penelitian ini digunakan untuk melihat perbedaan yang bermakna antara dua kelompok data (komparatif) yaitu variabel dependen (kadar kolesterol) sebelum terapi bekam dan variable dependen (kadar kolesterol) setelah terapi bekam. Uji statistic yang digunakan yakni uji $\mathrm{T}$ berpasangan.Jika variable baru hasil transformasi tidak berdistribusi normal, maka dipilih uji Wilcoxon.

\section{HASIL DAN PEMBAHASAN}

Responden yang dipilih menjadi sampel adalah pasien di rumah sehat Al- Hijamaah yang memiliki kolesterol $>200 \mathrm{mg} / \mathrm{dl}$ yang akan berbekam. Reponden dalam penelitian ini banyak dari laki-laki yaitu 18 orang atau sekitar $40 \%$. sebanyak 45 orang yaitu 27 orang atau sekitar 60\% lebih Untuk mengukur kolesterol peniliti menggunakan alat pengukur kolesterol Autocheck 3in1. Setelah data terkumpul, selanjutnya data tersebut disusun dalam bentuk table dengan menggunakan program komputerisasi yaitu Microsoft Excel. Kemudian tabel induk tersebut di masukkan ke SPSS 21 untuk di olah. Kemudian disajikan dalam bentuk tabel normalitas,frekuensi responden dan uji-t.

Tabel 1. Klasifikasi Penderita Hiperkolesterolemia berdasarkan Umur di Rumali Sehat Al-Ilijamaah

\begin{tabular}{lll}
\hline Usia (Tahun) & Jumlah & Presentase (\%) \\
\hline $20-45$ & 28 & 62,2 \\
\hline $45-65$ & 15 & 33,3 \\
\hline$>65$ & 2 & 4,4 \\
\hline Total & $\mathbf{4 5}$ & $\mathbf{1 0 0}$ \\
\hline
\end{tabular}

Sumber: SMK\&LI Data Primer, 2015

Berdasarkan tabel 1 diketahui bahwa usia penderita Hiperkolesterolemia di Rumah Sehat Al-Hijamaah terbanyak pada usia 20-45 yaitu sekitar 28 orang atau sekitar 62,2\%. Kemudian berusia 46-65 tahun yaitu sebanyak 15 orang atau sekitar $33,3 \%$. Usia yang paling sedikit berusia sekitar $>65$ tahun yaitu 2 orang atau $4,4 \%$.

Tabel 2. Klasifikasi Penderita Hiporkolesterolemia Berdasarkan Jenis Kelamin di Rumah Sehat Al-Ilijamaah

\begin{tabular}{lll}
\hline Jenis Kelamin & Jumlah & Presentase (\%) \\
\hline Laki-laki & 18 & 40,0 \\
\hline Perempuan & 27 & 60,0 \\
\hline Total & $\mathbf{4 5}$ & $\mathbf{1 0 0}$ \\
\hline Sumber: SMK\&LI Data Primer, 2015
\end{tabular}

Berdasarkan tabel 2 menunjukan kadar kolesterol sebelum terapi bekam di Rumah Sehat Al-Hijamaah, didapat yang memiliki kadar kolesterol >240 mg/ sebanyak 26 orang $(57,8 \%)$ dapat dikategorikan kadar kolesterol tinggi dan yang memiliki kadar kolesterol 200kolesterol setelah terapi bekam di klinik rumah sehat bekam yaitu sebanyak 22 orang $(48,9 \%)$ memiliki kadar kolesterol high atau $>240 \mathrm{mg} / \mathrm{dl}, 17$ orang (37,8\%) dengan kolesterol Borderline atau diantara 
$200-240 \mathrm{mg} / \mathrm{dl}$ dan 6 orang $(13,3 \%)$ dengan kadar kolesterol normal $(<200$ $\mathrm{mg} / \mathrm{dl}$ )

Berikut data kadar kolesterol sebelum dan sesudah dilakukan terapi bekam terhadap 45 responden.

Tabel 3. Klasifikasi Kadar Kolesterol pada Penderita Hiporkolesterolemia Berdasarkan Jenis Kelamin di Rumah Sehat Al-Ilijamaah setelah Terapi Bekam.

\begin{tabular}{ccc}
\hline Interpretasi & Jumlah & Presentase (\%) \\
\hline$<200 \mathrm{mg} / \mathrm{dl}$ & 6 & 13,3 \\
\hline $200-240 \mathrm{mg} . \mathrm{dl}$ & 17 & 37,8 \\
\hline
\end{tabular}

\begin{tabular}{ccc}
\hline$>240 \mathrm{mg} / \mathrm{dl}$ & 22 & 48,9 \\
\hline Total & $\mathbf{4 5}$ & $\mathbf{1 0 0}$ \\
\hline Sumber: SMK\&LI Data Primer, 2015 &
\end{tabular}

\section{Gambaran Kadar Kolesterol Pada Pasien Hiperkolesterolemia Sebelum dan Sesudah Terapi Bekam}

Berdasarkan tabel 5.5 diatas diketahui bahwa rata- rata kadar kolesterol sebelum di lakukan terapi bekam sebesar 262,84 $\mathrm{mg} / \mathrm{dl}$ dan rata- rata setelah dilakukan terapi bekam 239, $53 \mathrm{mg} / \mathrm{dl}$

Tabel 4. Kadar Kolesterol pada Responden Sebelum dan Sesudah dilakukan Terapi Bekam.

\begin{tabular}{|c|c|c|c|c|c|}
\hline \multirow{2}{*}{$\mathbf{N}$} & \multirow{2}{*}{ Variabel } & \multicolumn{2}{|c|}{ Kadar Kolesterol } & \multirow[t]{2}{*}{ Uji $t$} & \multirow[t]{2}{*}{ Value $p$} \\
\hline & & Rata-rata & Mean & & \\
\hline $\mathrm{i}$ & Sebelum Terapi & 262,84 & \multirow{2}{*}{23,31} & \multirow{2}{*}{2,64} & \multirow{2}{*}{0,010} \\
\hline 2 & Sesudah Terapi & 239,53 & & & \\
\hline & & Total & 45 & & 100 \\
\hline
\end{tabular}

Sumber: SMB GLL Data Primer, 2015

Hasil analisis statistik dengan uji $\mathrm{t}$ berpasangan pada responden sebelum dan sesudah terapi bekam menunjukkan nilai ttest $=2,64$ dengan nilai $\mathrm{p}=0,010(<0,05)$. Hal tersebut menunjukkan bahwa ada perbedaan antara kadar kolesterol sebelum dan sesudah terapi bekam.Perbedaan yang ditunjukkan dengan penurunan kadar kolesterol sebelum dansesudah pemberian terapi bekam ini ditunjukkan dengan nilai beda mean sebesar 23,31. Sedangkan jika dilihat dari nilai signifikan $(\mathrm{p}=0,010)$, maka nilainya kurang dari $a=0,05$. Hal tersebut dapat dijelaskan bahwa upaya penurunan kadar kolesterol darah dapat dilakukan terapi bekam.

\section{Interpretasi dan Diskusi Hasil}

Berdasarkan hasil penelitian di atas terhadap 45 responden yang diukur kadar kolesterol sebelum melakukan terapi bekam dan sesudah melakukan terapi diperoleh kadar kolesterol sebelum terapi bekam di klinik rumah sehat bekam yaitu sebanyak 57,8\% memiliki kadar kolesterol high atau $>240 \mathrm{mg} / \mathrm{dl}$ dan $42,2 \%$ dengan kolesterol Borderline atau diantara 200 $240 \mathrm{mg} / \mathrm{dl}$ dengan rerata kadar kolesterol sebelum terapi bekam yaitu 262,84.

Kadar kolesterol sesudah terapi bekam di klinik al-hijamaah yaitu sebanyak 48,9\% memiliki kadar kolesterol high atau $>240 \mathrm{mg} / \mathrm{dl}, \quad 37,8 \%$ dengan kolesterol Borderline High atau diantara 200 - 240 $\mathrm{mg} / \mathrm{dl}$ dan 13,3\% dengan kadar kolesterol normal $(<200 \mathrm{mg} / \mathrm{dl})$ yang dimana tidak terdapat pada kadar kolesterol normal sebelum terapi bekam. Dengan rerata kadar kolesterol sesudah terapi bekam yaitu 239,53 dengan nilai beda mean 23,31. Penelitian ini sejalan dengan yang dilakukan oleh Sri Widodo dengan nilai simpangan baku sebelum dan sesudah terapi bekam yaitu $27^{24}$. Hasil uji Independent $\mathrm{t}$ test nilai uji $\mathrm{t}=2,64$ dengan $\mathrm{p}$ value $=0,010<a=0,05$ yang berarti terdapat perbedaan kadar kolesterol yang signifikan sebelum dan sesudah dilakukan terapi bekam. Penurunan kadar kolesterol darah total pada penelitnian inin didukung 
juga dengan hasil penelitian oleh Naisari, bahwa terapi bekam dapat mereduksi kolesterol LDL pada laki-laki dan mempunyai efek pencegahan terhadap terjadinya aterosklerosis ${ }^{25}$. Majid B tahun 2008, melalui penelitiannya juga mendapatkan hasil bahwa terapi bekam basah dapat merubah lipoprotein darah perokok yaitu menurunkan kadar kolesterol total dan kadar LDL serta menaikkan $\mathrm{HDL}^{26}$. Penurunan kadar kolesterol yang dipengaruhi intervensi terapi bekam di duga karena adanya pengaruh mekanisme sistem hematolgi yang memberikan efek utama melalui jalur sistem regulasi koagulasi-antikoagulasi dengan peningkatan aliran darah dan peningkatan oksigenasi organ. Mengingat hepar merupakan tempat filtrasi darah dari berbagai zat toksisk yang masuk ke dalam tubuh, melalui mekanisme sistem imun inilah kadar kolesterol dalam tubuh dapat diturunkan

Adapaun mekanisme yang mendasari efek terapi bekam terhadap penurunan kadar kolesterol darah total, terbukanya barrier kulit akan meningkatkan fungsi eksresi kulit diantaranya mengeluarkan lipid dan substansi/ material yang bersifat hidrofobik. Terapi bekam basah dapat mengekskresikan material hidrofilik dan hidrofobik yang salah satu contohnya adalah lipoprotein ${ }^{24}$. Hasil dari penelitian ini juga sejalan dengan penelitian yang telah di ujikan di Iran yaitu pada beberapa sampel pemuda berusia 20-27 tahun untuk melihat pengaruhnya terhadap kadar kolesterol total, HDL dan LDL dan di dapatkan hasil signifikan pada kadar kolesterol total, HLD, LDL dengan menggunakan analisis SPSS. Di Iran terapi bekam khususnya terapi bekam basah telah di ujikan pada laki-laki, umur 1825 tahun dan tidak menderita antihiperlipidemia serta tidak mengkonsumsi makanan berenergi tinggi. Hasil penelitian ini menyipulkan bahwa terapi belam dapat mereduksi kolesterol LDL pada laki-laki dan mempunyai efik pencegahan terhadap aterosklerosis ${ }^{25}$.
Hasil penelitian ini memberikan refrensi tambahan dalam terapi bekam bahwasanya dapat menurunkan kadar kolesterol seseorang secara signifikan. Terapi bekam sendiri merupakan analogi dari proses eksresi yang dilakukan oleh organ ginjal. Komponen yang memungkinkan untuk diekskresikan melalui bekam meliputi produk- produk sisa metabolism tubuh, radikal bebas, substansi kimiawi dan biologi yang dilepaskan ke dalam cairan interstitial dan darah yang termasuk substansi hidrofilik dan atau hidrofobik yang termasuk didalamnya lipoprotein atau kolesterol ${ }^{24}$. Pola hidup selalu beraktifitas fisik dan tidak malas Salah satu penyebab hiperkolesterolemia salah satunya dikarenakan seseorang enggan melakukan aktifitas fisik sehubungan karena faktor seperti gaya hidup seseorang yang malas.

\section{KESIMPULAN}

Berdasarkan hasil penelitian tentang pengaruh terapi bekam terhadap penurunan kadar kolesterol pada penderita hiperkolesterolemia di Rumah Sehat AlHijamaah pada bulan Desember 2014 bulan Januari 2015 di dapatan kesimpulan sebagai berikut : Terdapat pengaruh penurunankadar kolesterol pada penderita hiperkolesterolemia setelah dilakukan terapi bekam dengan rerata kolesterol sesudah terapi bekam yaitu 239,53 dengan nilai beda $23,31 \mathrm{mg} / \mathrm{dl}$. Signifikansi Pvalue $=0.010$ dimana $\mathrm{a}<0,05$

\section{DAFTAR PUSTAKA}

1. Bull E. and Morrel J (2007). Kolesterol, Erlangga, Jakarta: Erlangga.

2. Price. Sylvia A., Wilson, Lorraine M (2006). Patofisiologi Konesep Klinis Proses-Proses Penyakit. Jakarta: EGC.

3. Soeharto, I (2004) Penyakit

Jantung Koroner dan Serangan Jantung Pencegahan Penyembuhan Rehabilitasi. 
Jakarta: PT. Gramedia Pustaka Utama.

4. WHO (2005). P.9 Physical Inactivity: A Global Public Health Problem. Sumber: http: //www .who.int/dietphysical activity/factsheet inactivity/en/ (diakses tanggal 24 oktober 2014).

5. Setiono, Laurentia Yustiana (2012). Dislipidemia Pada Obesitas Dan Tidak Obesitas Di Rsup Dr. Kariadi Dan Laboratorium Klinik Swasta Di Kota Semarang, Jurnal Media Medika Muda Karya Tulis Ilmiah

6. Fogoros, Richard N (2014). The Statin Drugs. Sumber : http://heartdisease .about.com/cs/_cholesterol/a/ statins.htm (diakses tanggal : 24Oktober- 2014)

7. Purbaningrum, Lukluk. dan Salmah Orbayinah (2012).

Pengaruh Kapsul Pleuratus Ostreatus terhadap Kadar Kolesterol pada Lanjut Usia Hiperkolesterolemia. Yogyakarta : Fakultas Kedokteran dan Ilmu Kesehatan Universitas Muhammadiyah Yogyakarta

8. Pramono, Ardi., Solikah Ulfah Kesuma, Nurul Hikma Tazkiana, dan Rahma Alma Yunita (2011). Pengaruh Rebusan Daun Sukun (Artocarpus altilis) terhadap Kadar Trigliserida, Kolesterol Total dan Low Density Lipoprotein (LDL) Serum Darah Tikus Putih ( Rattus norvegicus). Yogyakarta - Bagian Biokimia dan Anastesi Fakultas Kedokteran dan Kesehatan Universitas Muhammadiyah Yogyakarta

9. Nasihun, Taufiq R. Dan Eni Widayanti (2010). Penurunan Kadar Kolesterol Darah Akibat Seplemen Cangkang Udang Laut (Palaeman Sp) pada Tikus yang juga Mendapatkan Minyak Babi. Semarang :Bagian Biokimia Fakultas Kedokteran Universitas Kedokteran Islam Sultan Agung (UNISSULA)

10. Subhi, M (2009). Perbedaan Kadar Gula Darah Pasien Diabetes Mellitus Pada Pengobatan Bekam di Klinik Bashotan Holistik Center Masjid
Agung Jawa Tengah. Jurnal Kesehatan Masyarakat: Universitas Dipanegoro.

11. Jansen. S., Darwin Karim, Misrawati (2013). Efektifitas Terapi Bekam Terhadap Penurunan Tekanan Darah pada Penderita Hipertensi Primer di Klinik Al-Jawwad Pekanbaru. Sumber : http://repository.unri.ac.id/xmlui /bitstream/handle/123456789/52 $65 /$ susianaiansen,pdf? sequence $=$ (diakses : 24-Oktober-2014)

12. Al-Kaheel Abdel Daem (2012). Rahasia Pengobatan Dalam Islam. Jakarta: Amzah

13. Fatahillah (2007). Keampuhan Bekam Cetakan III. Jakarta : QultumMedia.

14. Baynes, John W, Marek H Dominiczak (2009). Medical Biochemistry, Third Edition, China : Mosby Elsevier

15. Fikri F (2009). Bahaya Kolesterol. Jogjakarta: Kelompok Penerbit ArRuzz Media.

16. Guyton, A.C., dan Hall, J.E (2008). Buku Ajar Fisiologi Kedokteran. Edisi 11. Jakarta: EGC.

17. Kumar V, Cotran RS, Robbins SL (2007). Buku ajar patologi $.7^{\text {nd }}$ ed, Vol. 2. Jakarta : Penerbit Buku Kedokteran EGC.

18. Harrison, Tinsley Randolph (2013). Harrison's Manual Of Medicine, $18^{\text {th }}$ Edition, North America : Mc Graw Hill.

19. Gray Jerry D (2014). Rasulullah Is My Doctor. Jakarta: Sinergi Publishing.

20. Umar Wadda A (2012). Bekam untuk 7 Penyakit Kronis. Solo: Thibbia.

21. Ridho Ahmad Ali (2012). Bekam Sinergi. Solo: Aqwamedika.

25. Sri Widodo, Khoiriyah. Efek Terapi Bekam Terhadap Kadar Kolesterol Total Pada Penderita Hiperkolesterolemia di KlinikBekam Center Semarang. Semarang : Fakultas Ilmu

Keperawatan dan Kesehatan, Universitas Muhammadiah Semarang

26. Niasari M., Kosari F. Dan Ahmadi A (2007). The Effect of Wet Cupping on Serum Lipid Concentration of 
Clinically Health Young Meng: $A$ Randomized Controled Trial. The Journal of Alternative and Complementary Medicine.

27. Majid B (2008). Kajian Terapi Bekam terhadap Profil Lipoprotein dan Komponen Darah Perokok. Tesis. Program Magister. Fakultas Biologi. Yogyakarta: Universitas Gadjah Mada. 